American Journal of Pharmaceutical Education 2017; 81 (9) Article 6076.

\title{
RESEARCH
}

\section{Identifying Shared Values for School-Affiliated Student Organizations}

\author{
Antonio A. Bush, PhD, ${ }^{a}$ Kaitlyn M. Buhlinger, PharmD, ${ }^{b}$ Jacqueline E. McLaughlin, PhD ${ }^{\mathrm{a}}$ \\ ${ }^{a}$ Division of Practice Advancement and Clinical Education, UNC Eshelman School of Pharmacy, Chapel Hill, \\ North Carolina \\ ${ }^{\mathrm{b}}$ Student Senate, UNC Eshelman School of Pharmacy, Chapel Hill, North Carolina \\ Submitted September 21, 2016; accepted January 19, 2017; published November 2017.
}

Objective. To identify shared values for student organizations.

Methods. A three-round Delphi approach was utilized to identify and prioritize shared values among student organization leadership. In round 1, student leaders selected 15 values from a list of 36 organizational values and were given an opportunity to include up to five suggestions not incorporated within the original list. Student leaders narrowed the 15 values to 12 in round 2 . The top 12 priorities were ranked in round 3 and participants were invited to write a brief statement regarding their perspectives of the results.

Results. Twelve shared values were identified and ranked: professional development, improving leadership of your members, advancing the role of pharmacy, planning quality events, networking, improving the academic experience for peers, community service, learning from pharmacy shadowing/ speakers, social outlet, recruitment/gaining student membership, attracting students to events, and gaining national/local attention or awards.

Conclusion. This study contributes to the small but growing body of literature concerning student organizations in pharmacy education and provides a foundation by which this work could be advanced. Given the importance of student organizations in promoting student development, identifying strategies for supporting and facilitating the effectiveness of these groups is critical for optimizing student outcomes and institutional effectiveness.

Keywords: student organizations, co-curricular, curriculum, pharmacy education

\section{INTRODUCTION}

Student organizations play an important role in doctor of pharmacy degree programs. For students, involvement in student organizations can promote the development of key professional and social skills, provide opportunities for relationship and network building, and create immersion opportunities in pharmacy and health care through activities such as service learning, volunteerism, clinical competitions, patient care projects, and seminars. ${ }^{1-3}$ Specifically, research suggests that engagement in student organizations can improve altruism, accountability, honor/integrity, organizational skills, and relationship skills in student pharmacists. ${ }^{1,2}$ Student organization involvement also remains an important aspect of a postgraduate application. ${ }^{4}$

At the institutional level, student organizations can also provide a number of important benefits, including, but not limited to, fostering alumni engagement, creating

Corresponding Author: Jacqueline McLaughlin, UNC Eshelman School of Pharmacy, Beard 326, Chapel Hill, NC 27599-7574. Tel: 919-966-4557. E-mail:

jacqui_mclaughlin@unc.edu strategic relationships with professional organizations, and complementing student skill development provided in the curriculum. Since student engagement in educationally purposeful activities is a critical aspect of student success, ${ }^{5}$ institutions have a vested interest in providing students with opportunities to engage in meaningful educational activities within and beyond the academic curriculum. In pharmacy education, there are a wide range of student organizations that represent a diversity of purposes, interests, specialties, skills, and activities. ${ }^{3}$ Student, faculty, and alumni involvement in organizations that align with institution or divisional goals can further promote success through retention, agency, and branding. ${ }^{6-9}$

There is little guidance or research concerning how to best position student organizations for success in the midst of rapidly evolving education and health care systems. As schools and colleges of pharmacy work to prepare aspiring pharmacists for the ongoing challenges of health care, ${ }^{10-12}$ it is timely to consider how student organizations might work with the institution and one another to foster student growth and development. As noted in prior research, for example, institutions should identify 


\section{American Journal of Pharmaceutical Education 2017; 81 (9) Article 6076.}

strategies that promote unity within the entire student body while also meeting the unique and diverse needs of the community. ${ }^{3,13}$ Understanding the shared goals of student organizations can help position an institution and its organizations to better support and draw upon institutional stakeholders to optimize outcomes.

Achieving our institutional goals will require strategic and intentional efforts to support student organizations. At the University of North Carolina (UNC) Eshelman School of Pharmacy, the school's transformed curriculum was implemented in fall 2015 with the goal of developing exemplary pharmacy practitioners, leaders and innovators, and lifelong learners. While the transformed curriculum specifically addresses academic experiences associated with re-engineered classroom experiences, increased opportunities for problem-solving and innovation, and enhanced early immersion into the patient care experience, ${ }^{10,14}$ it also gives consideration to the role of the co-curriculum in promoting student development of core skills and competencies.

The purpose of this study was to identify shared values for student organizations at the UNC Eshelman School of Pharmacy in an effort to inform ongoing curriculum design. This study was a first step toward creating a unified vision for the student organizations and fostering their capacity to prosper amid the school's curriculum transformation. It is also timely for all schools given the 2016 Accreditation Council for Pharmacy Education (ACPE) accreditation requirements emphasizing personal and professional development (Standard 4), affective domain elements (Standard 12.3), and assessment (Standard 25). ${ }^{15}$

\section{METHODS}

The Delphi technique has been used extensively to reach consensus in pharmacy education. Aronson and colleagues used a modified Delphi process with student pharmacists to develop a definition of professional engagement. ${ }^{16}$ Janke and colleagues used the technique to define competencies for student leadership development in pharmacy curricula. ${ }^{17}$ Mackellar and colleagues used a modified two-round Delphi survey to reach consensus on seven criteria to assess pharmacy students' communication skills with patients. ${ }^{18}$

This study used the Delphi technique to facilitate consensus building among student organization leadership at the UNC Eshelman School of Pharmacy. The Delphi technique is an iterative process in which experts are used to arrive at group consensus when little or no agreement exists. ${ }^{19,20}$ In this process, researchers gather experts, provide a question, and synthesize the feedback collected to assist the group in reaching agreement. ${ }^{20}$
The Delphi process has been traditionally conducted with the use of paper surveys. However, with the advancement of technology, e-Delphi research has become more prevalent than the traditional method due to it being more time and cost efficient and its potential to limit risks such as participant attrition. ${ }^{20,21}$ In this study, the e-Delphi Technique was incorporated with Sieber and SulzerAzaroff and colleagues' approaches to guide student organization leaders at the UNC Eshelman School of Pharmacy in identifying a list of core values. ${ }^{22-24}$ This study was exempt from full review by UNC's Institutional Review Board.

In fall 2015, students were invited to participate as "organizational value experts" if they were elected or appointed leaders for the 2015-2016 academic year from student organizations recognized by the school. One representative was invited for student organizations with 25 or fewer active members and two representatives were invited for student organizations with more than 25 active members. The participation of the president-elect or vice president was requested for all organizations.

In August 2015, a recruitment email was sent to the president and vice-president of 20 student organizations by the school's student senate president. Of those invited organizations, 15 organizations had 25 or more active members while five organizations had fewer than $25 \mathrm{ac}-$ tive members. In this email, the student leaders were asked to submit names and email addresses of organizational value experts using a Google Sheet (Mountain View, CA). These student leaders were then invited to participate in a three round Delphi study.

Round 1 of the study was conducted by email. In round 1, a list of 36 organizational values were included in a Qualtrics survey (Table 1). The list was created by the student senate president and vetted against the literature, student experiences, and the UNC Eshelman School of Pharmacy's strategic plan core values. The participants were asked to select any 15 items that reflected the values of the student organization they were representing for the study and were provided with an opportunity to include up to five suggestions that were not incorporated in the original list. The responses were analyzed through Qualtrics (Provo, UT) and the top 15 items were reformatted into a new Qualtrics survey in preparation for round 2 .

The second round was conducted during an in-person meeting to minimize participant attrition. Upon receiving a brief introduction, the participants were sent the list of 15 items through a Qualtrics survey and asked to select their top 10 items. The participants' responses were analyzed through Qualtrics and the top 10 items were reformatted into a new Qualtrics survey. Round 3 commenced 


\section{American Journal of Pharmaceutical Education 2017; 81 (9) Article 6076.}

Table 1. Original List of Organizational Items

1. Patient care opportunities

2. Philanthropy awareness/fundraising

3. Raising funding for organization's use

4. Social outlet

5. Networking

6. Gaining attention from the school

7. Gaining national/local attention or awards

8. Working with other organizations

9. Involving faculty

10. Planning quality events

11. Increasing number of events

12. Attracting students to events

13. Professional development

14. Learning from pharmacy shadowing/speakers

15. Community service

16. Pharmacy policy

17. Recruitment/gaining student membership

18. Maintaining exclusivity of organization

19. Advancing the role of pharmacy

20. Improving leadership of your members

21. Cultural diversity

22. Social media communication

23. Organizational reputation among peers/faculty

24. Improving the academic experience for peers

25. Research

26. Improving communication/presentation skills

27. Open discussion

28. Teaching others about pharmacy

29. Recruiting to the profession/school

30. Promoting interdisciplinary experiences

31. Preparedness for residency/work field

32. Decreasing stress of members

33. Maintaining a competitive extra-curricular environment

34. Incorporating religious/spiritual values into school/work

35. Advancing members for scholarship opportunities

36. Innovation/creativity in organization

immediately following the analysis of data from round two. In round 3, the participants were asked to rank their top 10 items.

Based on participant responses in round 3, the items were ranked according to mean scores, which were calculated according to weights for each position of an item. In other words, a ranking of 1 would receive 10 points, a ranking of 2 would receive 9 points, a ranking of 3 would receive 8 points, and so on, and these scores were summed and averaged by the total number of responses. The mean-ranked items were sent to respondents in a new Qualtrics survey and participants were invited to write a brief statement regarding their perspectives of the results. The researchers used thematic analysis to analyze the statements. ${ }^{24}$ Results are presented according to the final ranking list from round 3. Continuous data is presented as mean (standard deviation, SD).

\section{RESULTS}

Of the 34 organizational value experts invited to participate, $31(91 \%)$ completed the initial survey, representing $19(95 \%)$ of the 20 organizations recognized by the school. Rounds 2 and 3 of the study were conducted inperson. Twenty-nine $(85 \%)$ of the 34 invited organizational value experts participated. Of the 20 organizations invited, $18(90 \%)$ were represented. About $53 \%$ of the participants held a B.S. degree prior to being enrolled, $17 \%$ held a B.A. degree, and $30 \%$ earned no college degree prior to enrollment. The majority of the participants were between ages $21-25$ (83\%) while about $17 \%$ were over the age of 25 .

The participants most frequently selected the following 15 items from the original list of 36 items: professional development (selected by 68\%), improving leadership of your members (58\%), advancing the role of pharmacy $(42 \%)$, planning quality events $(71 \%)$, networking (58\%), improving the academic experience for peers $(39 \%)$, community service $(58 \%)$, learning from pharmacy shadowing/speakers (39\%), social outlet (48\%), recruitment/gaining student membership (48\%), attracting students to events (39\%), gaining national/local attention or awards (42\%), working with other organizations (48\%), philanthropy awareness/fundraising (42\%), and raising funding for organization's use (42\%) (Table 2). Seven additional items were suggested by participants; however, these items were generally aligned with other items on the original list.

Though we initially intended for the student leaders to select their top 10 items, items 9 to 12 each received 15 responses $(52 \%)$. Thus, 12 items were included in the final list of round 2: professional development (selected by $83 \%$ ), improving leadership of your members (79\%), advancing the role of pharmacy (66\%), planning quality events $(79 \%)$, networking (66\%), improving the academic experience for peers $(66 \%)$, community service $(52 \%)$, learning from pharmacy shadowing/speakers $(52 \%)$, social outlet (55\%), recruitment/gaining student membership (55\%), attracting students to events (52\%), and gaining national/local attention or awards (52\%) (Table 2).

Since 12 items were advanced to round 3, the mean rank score for each item was weighted on a scale of 1 to 12 , with a ranking of 1 multiplied by 12 , a ranking of 2 multiplied by 11 , and so on. The mean scores ranged from 9.86 (2.03) for professional development to 4.28 (2.85) for gaining national/local attention or awards (Table 2). The final 12 items were ranked in the following order, 
American Journal of Pharmaceutical Education 2017; 81 (9) Article 6076.

Table 2. Results by Round

\begin{tabular}{|c|c|c|c|c|}
\hline Items $^{\mathbf{a}}$ & $\begin{array}{l}\text { Round 1: Number } \\
\text { of Votes N (\%) }\end{array}$ & $\begin{array}{l}\text { Round 2: Number } \\
\text { of Votes N (\%) }\end{array}$ & $\begin{array}{l}\text { Round 3: Number of } \\
\quad \# 1 \text { Votes N (\%) }\end{array}$ & $\begin{array}{l}\text { Round 3: Mean-Ranked } \\
\text { Scores Mean (SD) }\end{array}$ \\
\hline 1. Professional development & $21(68)$ & $24(83)$ & $4(14)$ & $9.9(2.0)$ \\
\hline $\begin{array}{l}\text { 3. Advancing the role of } \\
\text { pharmacy }\end{array}$ & $13(42)$ & $19(66)$ & $8(28)$ & $8.2(3.8)$ \\
\hline 5. Networking & $18(58)$ & $19(66)$ & $0(0)$ & $6.9(2.3)$ \\
\hline $\begin{array}{l}\text { 6. Improving the academic } \\
\text { experience for peers }\end{array}$ & 12 (39) & $19(66)$ & $4(14)$ & $6.9(3.4)$ \\
\hline 7. Community service & $18(58)$ & $15(52)$ & $4(14)$ & $6.2(4.0)$ \\
\hline $\begin{array}{l}\text { 8. Learning from pharmacy } \\
\text { shadowing/speakers }\end{array}$ & 12 (39) & $15(52)$ & $1(3)$ & $5.6(2.8)$ \\
\hline $\begin{array}{l}\text { 11. Attracting students to } \\
\text { events }\end{array}$ & $12(39)$ & $15(52)$ & $0(0)$ & $4.4(2.6)$ \\
\hline $\begin{array}{l}\text { 12. Gaining national/local } \\
\text { attention or awards }\end{array}$ & $13(42)$ & $15(52)$ & $0(0)$ & $4.3(2.9)$ \\
\hline $\begin{array}{l}\text { 13. Working with other } \\
\text { organizations }\end{array}$ & $15(48)$ & N/A & $\mathrm{N} / \mathrm{A}$ & N/A \\
\hline $\begin{array}{l}\text { 14. Philanthropy awareness/ } \\
\text { fundraising }\end{array}$ & $13(42)$ & N/A & $\mathrm{N} / \mathrm{A}$ & N/A \\
\hline $\begin{array}{l}\text { 15. Raising funding for } \\
\text { organization's use }\end{array}$ & $13(42)$ & N/A & $\mathrm{N} / \mathrm{A}$ & N/A \\
\hline
\end{tabular}

Abbreviations: $\mathrm{SD}=$ Standard Deviation; N/A indicates that the item did not advance to other rounds

${ }^{a}$ Items are ordered by Round 3, Mean-Ranked Scores

with the percentage of \#1 votes indicated in parentheses: professional development (selected as top priority by $14 \%$ ), improving leadership of your members (17\%), advancing the role of pharmacy (28\%), planning quality events $(3 \%)$, networking $(0 \%)$, improving the academic experience for peers $(14 \%)$, community service $(14 \%)$, learning from pharmacy shadowing/speakers (3\%), social outlet $(3 \%)$, recruitment/gaining student membership $(3 \%)$, attracting students to events $(0 \%)$, and gaining national/local attention or awards $(0 \%)$. Of the 12 items considered as priorities, nine items received a number one ranking. Advancing the role of pharmacy and improving the leadership of your members accounted for almost half of the number one votes ( $45 \%$ or $13 / 29$ votes), while four items received only one vote each $(3.4 \%$ or $1 / 29$ votes each): planning quality events, social outlet, recruitment/ gaining student membership, and learning from pharmacy shadowing/speakers.

Upon completion of round 3, the participants were given a chance to voice their opinions by writing brief statements about the position of the top ranked items. Of the 29 participants present, 12 (41\%) provided a brief statement regarding the item rankings. Three topics emerged from the written comments. First, some comments $(n=3)$ raised questions concerning the responsibility of student organizations providing professional development. Second, some comments advocated for the importance of community service and ranking this priority higher $(n=5)$. Lastly, a few comments suggested moving the value of improving the academic experience for peers closer to the top of the list $(n=3)$.

\section{DISCUSSION}

It is critical that schools and colleges of pharmacy contribute to the growth of students who will become change agents in a health care system with evolving challenges. ${ }^{25}$ Given the importance of student organizations in promoting student development, identifying strategies for supporting and facilitating the effectiveness of these groups is critical for optimizing institutional effectiveness. This study demonstrates the use of the Delphi method for identifying the shared values of school-affiliated student organizations as a first step toward identifying opportunities for unifying student organizations and fostering their 


\section{American Journal of Pharmaceutical Education 2017; 81 (9) Article 6076.}

capacity to prosper amid the school's curriculum transformation. As noted below, our results have provided key data for informing the ongoing development of curricular and co-curricular experiences in the school's curriculum transformation process and may be useful for other schools and colleges of pharmacy.

Curriculum transformation can impact how students experience extra- and co-curricular activities. For example, in our transformed curriculum, students will rotate during years 2 and 3 so that half of the cohort will be in the field and the remaining students will be on campus for didactic coursework. ${ }^{10}$ This approach raises several important questions for student organizations. What does this mean for the school's student organizations that have historically operated on a more traditional class schedule? How might the academic curriculum transformation impact student involvement and executive leadership transitions? To "learn well," it is important that students are actively engaged with the course content both inside and outside of the classroom by "questioning, applying, testing, and reflecting on what they are learning." 26 Thus, while it is important that student academic experiences are transformed and made available through the core curriculum, extracurricular activities such as student organizations also provide unique opportunities for pharmacy students to develop skills. ${ }^{27}$

Historically, curriculum reform has been a world in which academic affairs (ie, faculty, lecturers, instructors) and student affairs staff have rarely, if at all, collaborated to the mutual benefit of the students served and the program. ${ }^{26}$ However, such relationships could prove advantageous. Data from this study is being used to inform decisions of the school's co-curricular working group, which makes recommendations to the school's Curriculum Transformation Steering Committee (CTSC) as it relates to co-curricular experiences. Among the five charges to the group was to re-engineer the student organizations to ensure they are co-curricular and complementary to the curricular experience.

Even for those not undergoing curricular transformation, the process described here can position schools and colleges of pharmacy to respond to accreditation requirements. Standard 4 of the 2016 ACPE Standards, for example, emphasizes that "the program imparts to the graduate the knowledge, skills, abilities, behaviors, and attitudes necessary to demonstrate self-awareness, leadership, innovation and entrepreneurship, and professionalism." 15 In addition, Standard 12.3 asserts that "cocurricular activities complement and advance the learning that occurs within the formal didactic and experiential curriculum" and Standard 25 requires a description of how the college or school "uses information generated by assessments related to its organizational effectiveness, mission and goals, didactic curriculum, experiential learning program, co-curriculum activities, and interprofessional education to advance overall programmatic quality." 15

Pharmacy student organizations have a rich history of providing students with critical personal and professional development opportunities. ${ }^{1-3}$ Using a method like the Delphi can help schools identify opportunities students have to gain skills through co-curricular experiences, an understanding of how these skills may align with program outcomes, and initiate conversations to assess potential skills gained through student organization involvement for accreditation purposes.

In addition to meeting accreditation requirements, the methods described here can help schools across the nation establish and promote the expectations for student organizations and other co-curricular activities. Since the Delphi method traditionally engages "experts," the sample size is small yet reflective of the most engaged students in these programs. Extending this sample out to the broader scope of the student body could help foster the culture of the institution, curriculum, and co-curriculum toward important value setting and learning experiences. Other institutions could model this study to gain a better understanding of student organizations and their positioning to core institutional and professional values.

The Delphi process should also help student organizations to reflect on what purpose they each serve within the school of pharmacy and profession. This starts with understanding what values they most associate themselves with and determining if this aligns with the intended purpose or mission of the organization. Participants can use the results of the Delphi study to understand the breadth of values and experiences offered through student organizations as a means to add value to their education in ways outside the classroom. While not all organizations have the same values, students should be able to choose those they participate in and reflect on the values gained by being involved in such organization. The identification of and reflection on these benefits by students is essential in personal growth, and can be initiated by organizations' individual reflection on their values as identified by the Delphi study.

This study contributes to discussions regarding the impact of co-curricular involvement on students' success. Involvement is a multi-dimensional construct that includes academic, social, and political layers (eg, social organizations, academic organizations, community service). Though previous scholarship suggests that student involvement plays a significant role on the undergraduate level, few studies have examined the impact of student 


\section{American Journal of Pharmaceutical Education 2017; 81 (9) Article 6076.}

involvement in graduate or professional education. ${ }^{29,30}$ However, several studies have explored motives for pharmacy student involvement. Cox and colleagues found that involvement in organizations increased as student pharmacists neared graduation. ${ }^{31}$ Roulin and colleagues found that the majority of the 197 students reported that their engagement stemmed from internal motives, but pressures to become more marketable for job placement served as a primary external motive towards the end of one's academic program. ${ }^{32}$ Philips and colleagues found that student pharmacists were motivated to pursue leadership positions in student organizations in an effort to exhibit to employers that they were well-rounded and increase their networking opportunities. ${ }^{27}$ One may deduce that the aforementioned research suggests that cocurricular involvement is relevant as students consider both the importance of securing accolades (ie, cv and resume) to become more marketable during job recruitment and also having the opportunity to actually gain useful skills to utilize during employment. This is an important conversation occurring both in pharmacy education as AACP is seeking to assess co-curricular experiences and across the horizon of higher education as student involvement continues to increase.

This research also extends a small but growing body of literature concerning student organizations in pharmacy education and provides a foundation by which this work could be advanced. Next steps, for example, could include the development of a shared mission for student organizations that provides newcomers with information on what to expect and current members with broadly accepted beliefs. Over time, organizations will need to "change their mission. . .in order to respond in purposeful ways to changing times, student characteristics and educational needs." ${ }^{33}$ In addition, our research team has initiated a study aimed at identifying skills that pharmacy students gain through involvement in a student organization at our school. The UNC Eshelman School of Pharmacy has a strong history of student involvement and evaluating the relationship between organizational culture and student involvement could help us better understand the mechanisms underlying student engagement in extra- and co-curricular activities and how these activities impact student development. The school's Educational Renaissance and curriculum transformation provide a unique and timely opportunity to consider these relationships while informing change that promotes student development and institutional effectiveness. ${ }^{10}$

This study is not without limitations. First, the sample size was low as only student leaders were used in the initial phase of prioritizing the values. The student leaders were generally upper-class students who had been heavily engaged in co-curricular activities. However, future studies should give consideration to the broader student body to ensure their commitment, gain their trust, and utilize their expertise as well. ${ }^{34}$ Additionally, two organizations were not represented due to scheduling conflicts. Inclusion of general members and increased attempts to have representation from all organizations should occur in future phases of the research. The timing of the study was also a limitation. The study was completed during the middle of the first semester of the transformed curriculum. Thus, students' priorities were primary linked to their experiences from the traditional curriculum. However, future work will include the perspectives of the first cohort of students who have experienced the transformed curriculum. Lastly, it is important to note that this study emphasized the student leaders' perceptions regarding the shared values for student organizations. Future studies may expand this work by exploring how the academy may perceive or rank student organization values and compare these held perspectives with those of the students to develop a more comprehensive understanding.

\section{CONCLUSION}

We engaged in this process understanding that each student organization has a distinct mission and set of values. The goal was not to modify the individual organization's mission nor create a mission that incorporates every aspect of each participating organizational mission. The purpose was to come to a consensus of shared values to inform efforts among organizations. Other universities could model this study to gain a better understanding of their organizations.

\section{ACKNOWLEDGMENTS}

We thank the student leaders for their involvement in the study and Brad Wingo, director of the Office of Curricular and Student Affairs, for his contributions.

\section{REFERENCES}

1. Poirier TI, Gupchup GV. Assessment of pharmacy student professionalism across a curriculum. Am J Pharm Educ. 2010;74(4): Article 62.

2. Kiersma ME, Plake KS, Mason HL. Relationship between admission data and pharmacy student involvement in extracurricular activities. Am J Pharm Educ. 2011;75(8):Article 155.

3. Scott MA, McLaughlin J, Shepherd G, et al. Professional organizations for pharmacy students on satellite campuses. Am J Pharm Educ. 2016;80(5):Article 78.

4. Bookstaver PB, Rudisill-Caulder CN, Smith KM, Quidley AD. Roadmap to Postgraduate Training in Pharmacy. 1st ed. New York: McGraw-Hill; 2013.

5. Kuh GD. Assessing what really matters to student learning: inside the National Survey of Student Engagement. Change. 2001;33(3): $10-17$. 


\section{American Journal of Pharmaceutical Education 2017; 81 (9) Article 6076.}

6. Tinto V. Leaving College. Rethinking the Causes and Cures of Student Attrition. 2nd ed. Chicago: University of Chicago Press; 1993.

7. Astin AW. Involvement the Cornerstone of Excellence. Chang Mag High Learn. 1985;17(4):35-39. doi:10.1080/00091383. 1985.9940532 .

8. Pinar M, Trapp P, Girard T, Boyt TE. Utilizing the brand ecosystem framework in designing branding strategies for higher education. Int J Educ Manag. 2011;25(7):724-739. doi:10.1108/ 09513541111172126.

9. Hurtado S, Ruiz A, Whang H. Assessing students' social responsibility and civic learning. In: Association for Institutional Research. New Orleans; 2012.

10. Roth MT, Mumper RJ, Singleton SF, et al. A renaissance in pharmacy education at the University of North Carolina at Chapel Hill. N C Med J. 2014;75(1):48-52.

11. The University of Mississippi School of Pharmacy. Curriculum Transformation Timeline and Competencies.

12. Jacobson D. PharmD curriculum transformation: an interview with vice dean Sharon Youmans.

13. Vyas D, Stinner N, Lindsey C. Promoting the professional development of students through the creation of a student organization on a satellite campus. J Am Pharm Assoc (2003). 2009;49(5):580. doi:10.1331/JAPhA.2009.09060.

14. UNC Eshelman School of Pharmacy. Pharm.D. Curriculum. 15. Aronson BD, Janke KK, Traynor AP. Investigating student pharmacist perceptions of professional engagement using a modified Delphi process. Am J Pharm Educ. 2012;76(7):125. doi:10.5688/ ajpe 767125.

16. Janke KK, Traynor AP, Boyle CJ. Competencies for student leadership development in doctor of pharmacy curricula to assist curriculum committees and leadership instructors. Am J Pharm Educ. 2013;77(10):222. doi:10.5688/ajpe7710222.

17. Mackellar A, Ashcroft DM, Bell D, James DH, Marriott J. Identifying criteria for the assessment of pharmacy students' communication skills with patients. Am J Pharm Educ. 2007;71(3). 18. Lindstone HA, Turoff M. The Delphi Method: Techniques and Applications. London: Addison-Wesley; 1975.

19. Cole ZD, Donohoe HM, Stellefson ML. Internet-based Delphi research: case-based discussion. Environ Manage. 2013;51(3):511523. doi:10.1007/s00267-012-0005-5.

20. Donohoe HM, Needham RD. Moving best practice forward: Delphi characteristics, advantages, potential problems, and solutions. Int J Tour Res. 2009;11(5):415-437. doi:10.1002/jtr.709.
21. Mertens D. Research and evaluation in education and psychology: integrating diversity with quantitative, qualitative, and mixed methods. 2010:527.

22. Sieber JE. Understanding the Perspective or Culture of Research Subjects and Other Stakeholders. Hayward: California State University; 1998.

23. Sulzer-Azaroff B, Fleming R, Tupa M, Bass R, Hamad C. Choosing objectives for a distance learning behavioral intervention in autism curriculum. Focus Autism Other Dev Disabil. 2008;23(1):2936. doi: $10.1177 / 1088357607311442$.

24. Braun V, Clarke V. Using thematic analysis in psychology. Qual Res Psychol. 2006;3(2):77-101. doi:10.1191/1478088706qp063oa.

25. Kerr RA, Beck DE, Doss J, et al. Building a sustainable system of leadership development for pharmacy: report of the 2008-09 Argus Commission. Am J Pharm Educ. 2009;73(8):S05. doi:10.5688/ aj7308S05.

26. Lattuca L, Stark JS. Shaping the College Curriculum: Academic Plans in Context. 2nd ed. San Francisco, CA: Jossey-Bass; 2009.

27. Phillips JA, McLaughlin MM, Gettig JP, Fajiculay JR, Advincula MR. An analysis of motivation factors for students' pursuit of leadership positions. Am J Pharm Educ. 2015;79(1):8. doi:10.5688/ ajpe79108.

28. Accreditation Council for Pharmacy Education. Accreditation Standards and Key Elements for the Professional Program in Pharmacy Leading to the Doctor of Pharmacy Degree. 2015.

29. Gardner SK, Barnes BJ, Astin AW, et al. Graduate student involvement: socialization for the professional role. J Coll Stud Dev. 2007;48(4):369-387. doi:10.1353/csd.2007.0036.

30. Gardner SK. If It Were Easy, Everyone Would Have a PhD:

Doctoral Student Success: Socialization and Disciplinary

Perspectives [dissertation]. Pullman: Washington State University; 2005.

31. Cox ER, Krueger KP, Murphy JE. Pharmacy student involvement in student organizations. J Pharm Teach. 1998;6(3):918. doi:10.3109/J060v06n03_03.

32. Roulin N, Bangerter A. Extracurricular activities in young applicants' résumés: what are the motives behind their involvement? Int J Psychol. 2013;48(5):871-880. doi:10.1080/00207594.

2012.692793.

33. Kuh GD, Kenzie J, Schuh JH, Whitt EJ, \& Associates. Student Success in College: Creating Conditions That Matter. 1st ed. San Francisco: Jossey-Bass; 2005.

34. Jones EA. Transforming the Curriculum: Preparing Students for a Changing World. San Francisco: Jossey-Bass; 2002. 